\title{
Gambaran Indeks Kepuasan Masyarakat di Puskesmas Tegal Angus pada Era Jaminan Kesehatan Nasional
}

\author{
Yusnita, Dini Widianti \\ Bagian Ilmu Kesehatan Masyarakat, Fakultas Kedokteran, Universitas YARSI
}

\begin{abstract}
Abstrak
Puskesmas sebagai salah satu badan layanan publik perlu menyusun indeks kepuasan masyarakat sebagai tolok ukur untuk menilai tingkat kualitas pelayanan. Perubahan puskesmas pada era Jaminan Kesehatan Nasional (JKN) menyangkut peran sebagai gate keeper untuk mengendalikan rujukan berjenjang. Tujuan penelitian ini adalah mengetahui tingkat indeks kepuasan masyarakat (IKM), deskripsi unsur-unsur IKM, dan unsur yang memengaruhi kepuasan pada pelayanan Puskesmas Tegal Angus pada era JKN. Penelitian ini adalah penelitian survei masyarakat. Penelitian dilakukan di Puskesmas Tegal Angus, Kecamatan Teluk Naga, Kabupaten Tangerang, Banten selama bulan Mei-Agustus 2016. Metode yang digunakan adalah studi potong lintang dengan responden adalah pasien yang telah mendapatkan pelayanan di puskesmas. Kuesioner yang digunakan adalah kuesioner indeks kepuasan masyarakat sesuai KepmenPAN RI Nomor: KEP/25/M.PAN/2/2004. Hasil penelitian ini menunjukkan IKM di Puskesmas Tegal Angus bernilai 63,5 yang termasuk kategori baik. Unsur pelayanan yang menyusun IKM sebagian besar masuk kategori baik. Unsur pelayanan yang masuk kategori kurang baik adalah kedisiplinan petugas pelayanan, kepastian jadwal dan biaya pelayanan, serta kecepatan pelayanan. Hasil peneltian ini dapat menjadi bahan penilaian terhadap unsur pelayanan yang masih perlu perbaikan dan menjadi pendorong setiap puskesmas untuk meningkatkan kualitas pelayanannya.
\end{abstract}

Kata kunci: Indeks kepuasan masyarakat, jaminan kesehatan nasional, puskesmas

\section{Puskesmas Tegas Angus Community Satisfaction Index in the National Health Coverage Era}

\begin{abstract}
Puskesmas as one of public health services should measure community satisfaction index (IKM) to ensure the qualtity of service. The role as gate keeper especially for referral system in National Health Coverage (JKN) is very challenging. The is research aim to understand level of community satisfaction index (IKM), describe indicators in satisfaction index and discover which indicator need to be increased. This is a survey study using cross sectional method. This study was held in Puskesmas Tegal Angus, Kecamatan Teluk Naga, Kabupaten Tangerang, Banten on May to August 2016. Community satisfaction index questionnaires based on KepmenPAN RI Nomor: KEP/25/M. PAN/2/2004 was used. The results showed that community satisfaction index of Puskesmas Tegal Angus categorized as having good quality of service with score of 63.5. However, there were four indicators that still need to be improved: discipline, accuracy of schedule adjustable expense, and speed of services. Community satisfaction index can be used as an assessment tools to improve the quality of service in public health center.
\end{abstract}

Key words: Community satisfaction index, nasional health coverage, public health center (puskesmas)

Korespondensi: Yusnita. Bagian Ilmu Kesehatan Masyarakat, Fakultas Kedokteran, Universitas YARSI. Jln. Letjen. Suprapto, Cempaka Putih, Jakarta Pusat. Telepon: 021-4244574. E-mail: yusnita@yarsi.ac.id 


\section{Pendahuluan}

Pusat kesehatan masyarakat atau puskesmas merupakan ujung tombak dalam pembangunan kesehatan di Indonesia. Menurut Keputusan Menteri Kesehatan RI Nomor: 128/MENKES/ SK/II/2004, puskesmas adalah unit pelaksana teknis dari Dinas Kesehatan Kabupaten/Kota yang bertanggung jawab dapat menyelenggarakan pembangunan kesehatan di suatu wilayah kerja. Sebagai unit pelaksana teknis dinas kesehatan kabupaten/kota puskesmas tentu menjadi bagian dari badan layanan publik. Sesuai dengan fungsi puskesmas sebagai pusat pelayanan kesehatan strata pertama, puskesmas bertanggung jawab menyelenggarakan pelayanan kesehatan tingkat pertama secara menyeluruh, terpadu, dan juga berkesinambungan. ${ }^{1}$

Namun, tidak dapat dipungkiri bila pelayanan kesehatan khususnya dari sektor publik masih banyak kendala dan hambatan terutama dalam hal kualitas pelayanan. Tingkat kepuasan masyarakat terhadap pelayanan dari sektor publik masih cukup rendah. Hal ini dibuktikan dari beberapa penelitian empiris terhadap kualitas pelayanan di birokrasi pemerintahan daerah. Salah satu upaya untuk meningkatkan kualitas pelayanan publik (masyarakat) seperti diamanatkan dalam Undang-Undang Republik Indonesia Nomor 25 Tahun 2000 tentang Program Pembangunan Nasional (PROPENAS), perlu disusun indeks kepuasan masyarakat sebagai tolok ukur untuk menilai tingkat kualitas pelayanan. Di samping itu, data indeks kepuasan masyarakat seyogianya dapat menjadi bahan penilaian terhadap unsur pelayanan yang diperlukan perbaikan dan juga menjadi pendorong setiap unit penyelenggara pelayanan untuk dapat meningkatkan kualitas

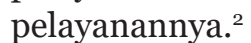

Jaminan Kesehatan Nasional itu atau JKN dilakukan oleh Badan Penyelenggara Jaminan Sosial (BPJS) Kesehatan dan telah dilaksanakan sejak 1 Januari 2014. Kedudukan dan peran fasilitas kesehatan primer termasuk puskesmas pada era JKN ini adalah sebagai penyelenggara untuk pelayanan kesehatan dasar yang berperan sebagai kontak pertama dan penapis rujukan sesuai dengan standar pelayanan medik. Pada era $\mathrm{JKN}$, kecuali dalam kondisi gawat darurat, semua peserta harus melalui fasilitas kesehatan (faskes) primer. Jika diperlukan untuk dirujuk seyogianya peserta akan memperoleh pelayanan di tingkat lanjutan atau rumah sakit. Strategi selanjutnya dalam peningkatan kualitas pelayanan kesehatan (yankes) primer, yaitu melalui kendali mutu. ${ }^{3}$

Salah satu cara untuk menilai mutu pelayanan puskesmas itu adalah menilai indeks kepuasan masyarakat di puskesmas. Puskesmas sebagai salah satu ujung tombak pelaksanaan Jaminan Kesehatan Nasional akan mengalami beberapa perubahan pada era JKN ini, misalnya jumlah kunjungan yang meningkat dan penerimaan dana kapitasi dari BPJS Kesehatan yang cukup besar sehingga dapat digunakan untuk meningkatkan pelayanan serta pengadaan sarana dan prasarana kesehatan di puskesmas sekaligus harus mampu menjadi gate keeper untuk dapat mengendalikan rujukan berjenjang. Fungsi sebagai gate keeper ini mengharuskan agar puskesmas menghadapi masyarakat itu secara langsung yang cenderung ingin berobat di fasilitas kesehatan lanjutan atau rumah sakit daripada di puskesmas.

Di lain pihak, puskesmas itu juga diharuskan meningkatkan mutu pelayanannya karena pasien dapat berpindah ke fasilitas kesehatan primer lain seperti klinik di sekitar puskesmas itu. Bila dahulu puskesmas hanya secara pasif menerima pasien dan cenderung melayani pasien seadanya maka sekarang puskesmas harus mampu aktif mengelola pasien dan bersaing dengan fasilitas kesehatan primer yang lainnya. Puskesmas Tegal Angus adalah salah satu puskesmas yang terletak di Kecamatan Teluk Naga, Kabupaten Tangerang, Banten yang mempunyai peserta JKN terdaftar cukup besar, yaitu kurang lebih 25.00o peserta. Oleh karena itu, menarik untuk mengetahui indeks kepuasan masyarakat di Puskesmas Tegal Angus pada era Jaminan Kesehatan Nasional.

Penelitian ini bertujuan mengetahui tingkat indeks kepuasan masyarakat (IKM), deskripsi unsur-unsur IKM, dan juga unsur apakah yang menyebabkan masyarakat kurang puas dengan pelayanan Puskesmas Tegal Angus pada era JKN.

\section{Metode}

Penelitian ini adalah penelitian survei masyarakat dengan metode cross sectional. Cara penetapan sampel dilakukan dengan quota sampling sesuai Keputusan Menteri Pendayagunaan Aparatur Negara RI Nomor: KEP/25/M.PAN/2/2004 tentang Pedoman Umum Penyusunan Indeks Kepuasan Masyarakat Unit Pelayanan Instansi Pemerintah. Responden ditetapkan minimal 150 orang dari jumlah populasi penerima layanan dengan dasar ("jumlah unsur" +1 ) $\times 10=$ 
Tabel 1 Kategorisasi Mutu Pelayanan

\begin{tabular}{cccl}
\hline $\begin{array}{c}\text { Nilai Interval } \\
\text { IKM }\end{array}$ & $\begin{array}{c}\text { Nilai Interval } \\
\text { Konversi IKM }\end{array}$ & $\begin{array}{c}\text { Mutu } \\
\text { Pelayanan }\end{array}$ & $\begin{array}{c}\text { Kinerja Unit } \\
\text { Pelayanan }\end{array}$ \\
\hline $1,00-1,75$ & $25,00-43,75$ & D & Tidak baik \\
$1,76-2,50$ & $43,76-62,50$ & C & Kurang baik \\
$2,51-3,25$ & $62,51-81,25$ & B & Baik \\
$3,26-4,00$ & $81,26-100,00$ & A & Sangat baik \\
\hline
\end{tabular}

Sumber: Kemenkes RI ${ }^{1}$

jumlah responden $(14+1) \times 10=150$ responden. Responden penelitian dipilih secara acak dengan consecutive sampling. Penelitian dilakukan di Puskesmas Tegal Angus, Kecamatan Teluk Naga, Kabupaten Tangerang, Banten periode bulan Mei-Agustus 2016.

Instrumen penelitian ini adalah kuesioner pilihan menggunakan skala Likert. Peubah yang diamati adalah variabel dependen IKM dan variabel independen yang terdiri atas prosedur pelayanan, persyaratan pelayanan, juga kejelasan petugas pada pelayanan, kedisiplinan petugas, tanggung jawab petugas pelayanan, kemampuan petugas pelayanan tersebut, kecepatan pelayanan, keadilan untuk mendapat pelayanan, kesopanan dan keramahan para petugas, kewajaran biaya pelayanan, kepastian biaya pelayanan, kepastian jadwal pelayanan, kenyamanan lingkungan, serta keamanan pelayanan.

Data yang dikumpulkan dalam penelitian ini merupakan data primer, yaitu data yang diperoleh langsung dari responden melalui wawancara tatap muka atau face-to-face interviews dengan menggunakan kuesioner terstruktur. Kuesioner dibagikan pada waktu jam pelayanan di lokasi penelitian. Analisis data dilaksanakan tiga tahap. Tahap pertama kuesioner yang sudah diisi itu dilakukan pembersihan data dan diberi koding. Jawabannya sesuai dengan skala Likert. Untuk kategori tidak baik diberi nilai persepsi 1, kurang baik diberikan nilai persepsi 2 , baik diberi nilai persepsi 3, sangat baik diberikan nilai persepsi 4. Pada tahap kedua dilakukan entri data, yaitu memasukkan data ke dalam sheet tabel isian yang terdiri atas 14 unsur kategori pelayanan. Tahap ketiga menghitung nilai rata-rata per unsur kategori pelayanan dan nilai indeks tiaptiap unit pelayanan. Nilai rata-rata per unsur kategori pelayanan diperoleh dari penjumlahan nilai tiap-tiap unsur kategori pelayanan sesuai jumlah kuesioner yang telah diisi oleh responden, kemudian dibagi dengan jumlah responden yang mengisi. Nilai rata-rata tertimbang per unsur kategori pelayanan diperoleh dari perkalian nilai rata-rata per unsur kategori pelayanan dengan 0,071. Nilai indeks unit pelayanan diperoleh dari penjumlahan 14 unsur nilai rata-rata tertimbang kategori pelayanan. IKM diperoleh dari nilai indeks unit pelayanan dikali nilai dasar 25 .

Kategorisasi hasil pengukuran IKM dapat dilihat pada Tabel 1.

\section{Hasil}

Karakteristik responden merupakan gambaran mengenai responden penelitian ini. Deskripsi karakteristik responden dikelompokkan menjadi beberapa kelompok meliputi usia, jenis kelamin, pendidikan yang terakhir, serta pekerjaan seperti terlihat pada Tabel 2.

Berdasarkan atas hasil penelitian dan setelah dilakukan tabulasi data diperoleh nilai indeks kepuasan dari masyarakat per unsur pelayanan pada Puskesmas Tegal Angus sudah baik seperti terlihat pada Tabel 3 .

Nilai IKM Puskesmas Tegal Angus sebesar $2,54 \times 25=63,54$. Jika dikonversi dengan Tabel 1 maka IKM Puskesmas Tegal Angus masuk dalam kategori baik.

Ada beberapa unsur pelayanan yang memiliki tingkat kepuasan yang kurang baik seperti dapat dilihat pada Tabel 4 .

\section{Pembahasan}

Usia pada seseorang dapat mencerminkan kondisi fisik. Dalam kaitannya dengan kesehatan, usia sebenarnya mampu mencerminkan kebutuhan perawatan kesehatan pada diri seseorang. Untuk keperluan perbandingan, WHO seperti dikutip Notoatmodjo ${ }^{4}$ menganjurkan pembagian usia itu berdasar atas tingkat kedewasaan menjadi tiga kategori sebagaimana terdapat pada Tabel 2.

Tabel 2 menunjukkan bahwa sebagian besar responden itu $(80,7 \%)$ adalah usia muda dan dewasa, sedangkan sebanyak 19,3\% berusia tua. Penelitian ini mengukur kepuasan masyarakat sehingga responden yang dipilih memang berusia 
Tabel 2 Karakteristik Responden

\begin{tabular}{lcc}
\hline Karakteristik Responden & $\begin{array}{c}\text { Frekuensi (Orang) } \\
\mathbf{n = 1 5 0}\end{array}$ & Persentase (\%) \\
\hline Usia (tahun) & & \\
$15-49$ & 121 & 80,7 \\
$\geq 50$ & 29 & 19,3 \\
Jenis kelamin & 74 & 49,3 \\
Laki-laki & 76 & 50,7 \\
Perempuan & & \\
Tingkat pendidikan & & \\
SD ke bawah & 84 & 56,0 \\
SLTP & 34 & 22,7 \\
SLTA & 31 & 20,7 \\
Diploma & 1 & 0,6 \\
S-1 & 0 & - \\
S-2 & 0 & - \\
Pekerjaan & & \\
PNS/TNI/Polri & 2 & 1,3 \\
Pegawai swasta & 13 & 8,7 \\
Wiraswasta & 18 & 12,0 \\
Pelajar/mahasiswa & 3 & 2,0 \\
Ibu rumah tangga & 114 & 76,0 \\
\hline
\end{tabular}

di atas 15 tahun yang dianggap karena sudah cukup matang untuk memberikan pendapat.

Jenis kelamin dapat menunjukkan kondisi fisik seseorang. Dalam hal keterkaitannya dengan kesehatan, jenis kelamin sering kali memberikan arti akan kekuatan fisik seseorang. Responden penelitian ini hampir berimbang antara laki-laki dan perempuan. Responden penelitian ini adalah pasien yang mendapat pengobatan di puskesmas sehingga dapat dikatakan bahwa jumlah pasien laki-laki dan perempuan hampir sama.

Tingkat pendidikan mampu mencerminkan tingkat intelektualitas seseorang. Kondisitersebut sering kali berhasil mencerminkan pemilihan lokasi untuk mendapatkan pelayanan kesehatan. Tingkat pendidikan responden terbesar adalah SD ke bawah sebanyak $56 \%$. Hal ini sesuai dengan keadaan demografi di wilayah kerja Puskesmas Tegal Angus yang merupakan daerah menengah ke bawah. Untuk mencerminkan status sosial

Tabel 3 Indeks Kepuasan Masyarakat di Puskesmas Tegal Angus

\begin{tabular}{clcc}
\hline No. & Indikator & Nilai Rata-rata & $\begin{array}{c}\text { Nilai Rata-rata } \\
\text { Tertimbang }\end{array}$ \\
\hline 1 & Prosedur pelayanan & 2,45 & 0,17 \\
2 & Persyaratan pelayanan & 2,56 & 0,18 \\
3 & Kejelasan petugas pelayanan & 2,53 & 0,18 \\
4 & Kedisplinan petugas pelayanan & 2,43 & 0,17 \\
5 & Tanggungjawab petugas pelayanan & 2,64 & 0,19 \\
6 & Kemampuan petugas pelayanan & 2,78 & 0,20 \\
7 & Kecepatan pelayanan & 2,48 & 0,18 \\
8 & Keadilan mendapatkan pelayanan & 2,64 & 0,19 \\
9 & Kesopanan dan keramahan petugas & 2,52 & 0,18 \\
10 & Kewajaran biaya pelayanan & 2,71 & 0,19 \\
11 & Kepastian biaya pelayanan & 2,44 & 0,17 \\
12 & Kepastian jadwal pelayanan & 2,44 & 0,17 \\
13 & Kenyamanan lingkungan & 2,52 & 0,18 \\
14 & Keamanan lingkungan & 2,65 & 0,19 \\
& & & $\mathbf{2 , 5 4}$ \\
\hline
\end{tabular}


Tabel 4 Tingkat Kepuasan per Unsur Pelayanan di Puskesmas Tegal Angus

\begin{tabular}{clcl}
\hline No. & Indikator & Nilai Rata-rata & Kategori \\
\hline 1 & Prosedur pelayanan & 2,45 & Kurang baik \\
2 & Persyaratan pelayanan & 2,56 & Baik \\
3 & Kejelasan petugas pelayanan & 2,53 & Baik \\
4 & Kedisplinan petugas pelayanan & 2,43 & Kurang baik \\
5 & Tanggungjawab petugas pelayanan & 2,64 & Baik \\
6 & Kemampuan petugas pelayanan & 2,78 & Baik \\
7 & Kecepatan pelayanan & 2,48 & Kurang baik \\
8 & Keadilan mendapatkan pelayanan & 2,64 & Baik \\
9 & Kesopanan dan keramahan petugas & 2,52 & Baik \\
10 & Kewajaran biaya pelayanan & 2,71 & Baik \\
11 & Kepastian biaya pelayanan & 2,44 & Kurang baik \\
12 & Kepastian jadwal pelayanan & 2,44 & Kurang baik \\
13 & Kenyamanan lingkungan & 2,52 & Baik \\
14 & Keamanan lingkungan & 2,65 & Baik \\
\hline
\end{tabular}

seseorang dapat dilihat dari jenis pekerjaannya. Jenis pekerjaan responden yang paling banyak adalah ibu rumah tangga, yaitu $76 \%$.

Indeks kepuasan masyarakat digunakan untuk mengetahui bagaimana tanggapan masyarakat pengguna layanan kesehatan terhadap pelayanan yang telah diberikan. Indeks ini dapat digunakan sebagai tolok ukur kualitas pelayanan Puskesmas Tegal Angus, apakah sudah memenuhi standar pelayanan minimal yang telah disyaratkan oleh pemerintah.

Kepuasan masyarakat itu dapat diketahui dengan melihat kualitas pelayanan pada tiaptiap indikator yang sudah ditentukan, dimulai dengan menganalisis indikator yang ada. Setiap item indikator dianalisis, kemudian skor item indikator tersebut dihitung rata-ratanya untuk menganalisis kualitas kinerja setiap indikator. Setelah semua indikator diukur, baru kemudian total skor keseluruhan 14 indikator yang ada dalam penelitian ini dihitung rata-ratanya untuk menentukan indeks kepuasan masyarakat.

Puskesmas Tegal Angus mengalami kenaikan jumlah kunjungan pasien sejak JKN diberlakukan. Pada tahun 2016 ada 29.00o penduduk di wilayah kerja Puskesmas Tegal Angus yang terdaftar sebagai peserta BPJS kategori PBI (penerima bantuan iuran) yang sebelumnya berasal dari peserta jaminan kesehatan masyarakat miskin (Jamkesmas). Pada era JKN, jumlah kunjungan pasien di Puskesmas Tegal Angus meningkat $30 \%$, artinya dengan peningkatan beban kerja Puskesmas Tegal Angus berhasil mendapatkan kepuasan masyarakat dengan kategori baik.

Berdasar atas Tabel 4, unsur pelayanan yang masih kurang baik sehingga masyarakat kurang puas mengenai kedisiplinan petugas pelayanan, kepastian tentang jadwal pelayanan, kepastian biaya pelayanan, dan kecepatan pelayanan.

Kedislipinan petugasmerupakankesungguhan petugas dalam memberikan pelayanan terutama terhadap konsistensi waktu kerja sesuai dengan ketentuan yang berlaku. Keluhan pada unsur ini berhubungan dengan ketersediaan petugas di unit pelayanan puskesmas. Pasien mengeluhkan keterlambatan para petugas yang datang, dengan demikian menyebabkan pasien menunggu.

Kepastian jadwal pelayanan itu merupakan pelaksanaan waktu pelayanan yang sesuai dengan ketentuan yang telah ditetapkan. Unsur kepastian jadwal pelayanan sangat berhubungan dengan unsur kedisiplinan petugas karena pelayanan tidak akan berjalan jika tidak ada petugas. Jika kesiplinan petugas masih kurang maka tentu saja akan memengaruhi kepastian jadwal pelayanan.

Kepastian biaya pelayanan dinilai berdasar atas kesesuaian antara biaya yang dibayarkan dan biaya yang telah ditetapkan. Di Puskesmas Tegal Angus, ada tiga kategori pasien menurut pembiayaan, yaitu pasien umum, pasien kartu sehat, dan pasien BPJS. Pasien umum membayar dari kantung sendiri jumlah biaya yang sesuai pelayanan yang diberikan puskesmas. Jumlah biaya sesuai dengan retribusi daerah yang telah ditempel di loket pelayanan Puskesmas Tegal Angus. Pasien kartu sehat adalah pasien yang tidak mampu, tetapi tidak termasuk penerima kartu BPJS PBI. Pasien kartu sehat tidak membayar saat berobat ke puskesmas, biaya pengobatan yang ditanggung Pemerintah Daerah Kabupaten Tangerang. Pasien BPJS berobat ke puskesmas tidak membayar karena sudah membayar iuran. 
Salah satu kelemahan penelitian ini adalah tidak membedakan responden itu berdasar atas jenis pembiayaan sehingga kemungkinan kurangnya nilai unsur kepastian tentang biaya pelayanan ini berasal dari responden pasien umum yang harus membayar sendiri pengobatannya di Puskesmas Tegal Angus.

Kecepatan pelayanan dinilai dari target waktu pelayanan yang dapat diselesaikan dalam waktu yang telah ditentukan oleh unit penyelenggara pelayanan di Puskesmas Tegal Angus. Sayangnya, Puskesmas Tegal Angus belum menentukan batas waktu setiap pelayanan yang diberikan. Keluhan dari pasien yang berhubungan dengan kecepatan pelayanan lebih disebabkan oleh waktu tunggu yang lama untuk mendapatkan pelayanan. Hal ini berhubungan juga dengan unsur kedislipinan dan kepastian jadwal pelayanan. Jika petugas kurang disiplin dengan datang terlambat dan tidak ada kepastian dimulainya waktu pelayanan maka pasien menunggu lebih lama dan menganggap kecepatan pelayanan menjadi kurang baik.

Unsur kepuasan dari masyarakat yang kurang pada era JKN ini harus segera direspons oleh manajemen dan staf Puskesmas Tegal Angus. Oleh karena saat ini jumlah peserta BPJS di Puskesmas Tegal Angus cukup besar, yaitu 29.000 peserta sehingga jika peserta tidak puas maka peserta BPJS dapat memindahkan provider di layanan primer yang juga melayani BPJS seperti klinik umum. Demikian juga jika pasien umum yang membayar sendiri tidak puas mereka dapat pindah ke penyedia layanan kesehatan lainnya.

Puskesmas dapat menggunakan hasil indeks kepuasan dari masyarakat ini sebagai masukan untuk meningkatkan kinerjanya dalam melayani masyarakat di wilayah kerja mereka. Puskesmas diharapkan terus meningkatkan kinerja untuk meningkatkan mutu pelayanan sehingga dapat meningkatkan indeks kepuasan masyarakat itu. Puskesmas perlu melakukan upaya khusus untuk meningkatkan kinerja dalam aspek kedisiplinan petugas, kepastian jadwal pelayanan, kepastian biaya pelayanan, dan kecepatan pelayanan.

\section{Simpulan}

Indeks kepuasan masyarakat di Puskesmas Tegal Angus sudah baik. Tingkat kepuasan masyarakat berdasar unsur pelayanan sebagian besar sudah baik, sedangkan unsur pelayanan yang membuat masyarakat kurang puas meliputi kedisiplinan petugas pelayanan, kepastian jadwal pelayanan, kepastian tentang biaya pelayanan, dan kecepatan pelayanan.

\section{Ucapan Terima Kasih}

Penelitian ini dibiayai dari dana hibah dosen pemula Direktorat Jenderal Riset dan Pengabdian Masyarakat, Kementerian Riset, Teknologi, dan Pendidikan Tinggi RI Tahun Anggaran 2015. Terima kasih juga kepada Lembaga Penelitian Universitas YARSI atas bimbingannya.

\section{Daftar Pustaka}

1. Kementerian Kesesehatan RI. Keputusan Menteri Kesehatan Nomor: 128/Menkes/ SK/II/2004 tentang Kebijakan Dasar Pusat Kesehatan Masyarakat.

2. Kementerian Pendayagunaan Aparatur Negara RI. Keputusan Menteri Pendayagunaan Aparatur Negara Nomor: KEP/25/M.PAN/2/2004 tentang Pedoman Umum Penyusunan Indeks Kepuasan Masyarakat Unit Pelayanan Instansi Pemerintah.

3. Gufron A. Penerapan jaminan kesehatan nasional di unit pelayanan kesehatan. Makalah Seminar. YARSI Meeting in Public Health 2014: Dokter Layanan Primer di Era Jaminan Kesehatan Nasional. Gedung YARSI Lantai 12. Juni 2014.

4. Notoatmodjo S. Kesehatan masyarakat. Ilmu dan seni. Jakarta: Rineka Cipta; 2014. 